\title{
A contribution to the tick (Acari: Ixodidae) fauna of Turkey: The first record of Ixodes inopinatus Estrada-Peña, Nava \& Petney
}

\author{
Ahmet BURSALI ${ }^{1}$ (D), Șaban TEKIN ${ }^{2,3}$ (D), Adem KESKIN ${ }^{1,4}$ (D) \\ ${ }^{1}$ Department of Biology, Faculty of Sciences and Arts, Tokat Gaziosmanpaşa University, Taşllçiftlik, Tokat, Turkey \\ ${ }^{2}$ Department of Basic Medical Sciences, Faculty of Medicine, University of Health Sciences, Üsküdar, İstanbul, Turkey \\ ${ }^{3}$ Genetic Engineering and Biotechnology Institute, TÜBİTAK Marmara Research Center, Kocaeli, Turkey \\ ${ }^{4}$ Corresponding author: adem.keskin@gop.edu.tr
}

Received: 20 March 2020

Accepted: 10 June 2020

Available online: 29 July 2020

ABSTRACT: Ticks are blood-sucking ectoparasites of terrestrial vertebrates. The genus Ixodes Latreille is the largest among hard ticks, and the members of the genus are spread around the world. In the present study, we reported presence of Ixodes inopinatus Estrada-Peña, Nava \& Petney, 2014 in Turkey for the first time. The specimens of I. inopinatus (1 male, 6 females) were collected from cattle in Ordu province, Turkey.

Keywords: Hard ticks, host associations, vectors, Turkey.

Zoobank: http://zoobank.org/4C24E3D1-8E34-4B24-B331-D9CEAF27D089

Ticks are important ectoparasites, causing a variety of serious infectious diseases in humans and domestic animals. Turkey is a Eurasian country occupying 783,562 square kilometers including Anatolian peninsula and Thrace. The territory of Turkey lies between latitudes $35^{\circ}$ - $43^{\circ}$ North and longitudes $25^{\circ}-45^{\circ}$ East and is divided into seven geographic regions. Each region has specific climate, vegetation and wild life allowing a suitable habitat for various tick species.

Turkish tick fauna is currently composed of 51 species; 43 species from family Ixodidae and 8 species from family Argasidae (Bursali et al., 2012; Kar et al., 2017; Keskin et al., 2014; Orkun and Karaer, 2018; Keskin and ErciyasYavuz, 2019). The genus Ixodes Latreille is the largest among ixodid ticks; and the members of the genus is spread around the world. To date, approximately 261 species of the genus Ixodes are known worldwide (Guglielmone et al., 2014, 2020; Onofrio et al., 2020), but this number are increasing with the new studies. In Turkey, to date, a total of 13 species of the genus Ixodes are identified: Ixodes acuminatus Neumann, Ixodes arboricola Schulze \& Schlottke, Ixodes crenulatus Koch, Ixodes eldaricus Djaparidze, Ixodes festai Tonelli-Rondelli, Ixodes frontalis (Panzer), Ixodes gibbosus Nuttall, Ixodes hexagonus Leach, Ixodes laguri Olenev, Ixodes redikorzevi Olenev, Ixodes ricinus (L)., Ixodes simplex Neumann, and Ixodes vespertilionis Koch (Bursali et al., 2012; Keskin et al., 2014; Kar et al., 2017; Orkun and Karaer, 2018; Keskin and Erciyas-Yavuz, 2019).

During our parasitological survey on ticks in the Black Sea Region of Turkey, we collected a number of Ixodes ticks (12 males, 49 females, 5 nymphs) on domestic cattle in 2006 from Ordu Province. This province is located the coastal strip of the Black Sea Region of Turkey. It has a temperate and humid climate. The mean annual precipitation is $1152 \mathrm{~mm}$, and the precipitation regime is the Black
Sea Rainfall Type. The mean annual temperature is 13.8 ${ }^{0} \mathrm{C}$. On average, 143 days of the year are rainy. The average relative humidity is $74.7 \%$ (Karaman et al., 2012). All of them were placed into labeled small plastic tubes containing 70\% ethanol and sent to Acarology Laboratory, Department of Biology, Tokat Gaziosmanpaşa University, Tokat, Turkey. Using of descriptions and identification keys given by Filippova (1977) and Estrada-Peña et al. (2017), ticks were identified as I. ricinus (11 males, 43 females, 5 nymphs), and Ixodes inopinatus Estrada-Peña, Nava, and Petney ( 1 male and 6 females). This is the first report of $I$. inopinatus in Turkey.

Ixodes inopinatus has been described among the specimens of I. ricinus specimens (Estrada-Peña et al., 2014). It is share some morphological features with other Palearctic Ixodes species; therefore I. inopinatus might have been historically confused with and erroneously reported as Palearctic Ixodes species, especially I. ricinus (EstradaPeña et al., 2014; Chitimia-Dobler et al., 2018). Presence of I. inopinatus has been documented from Austria, Portugal, Romania, Spain, and Tunisia.

Adults of I. inopinatus can be separated from the most related species, I. ricinus, by the combination of following characters. Punctations on the dorsal scutum are larger and conscutal setae are longer in the male of I. inopinatus than in I. ricinus. In addition, the pre-genital and median plates in I. inopinatus are with larger and deeper punctuation than in I. ricinus. Male of I. inopinatus has only one row of lateral conscutal setae (the second row can be observed only in the central part of idiosoma) between the lateral margin of the idiosoma and the marginal groove (Figs 1A, B), whereas there are several rows of lateral conscutal setae in I. ricinus (Figs 2A, B). The females of I. inopinatus have deep and large punctations in the central field of the scutum, which 

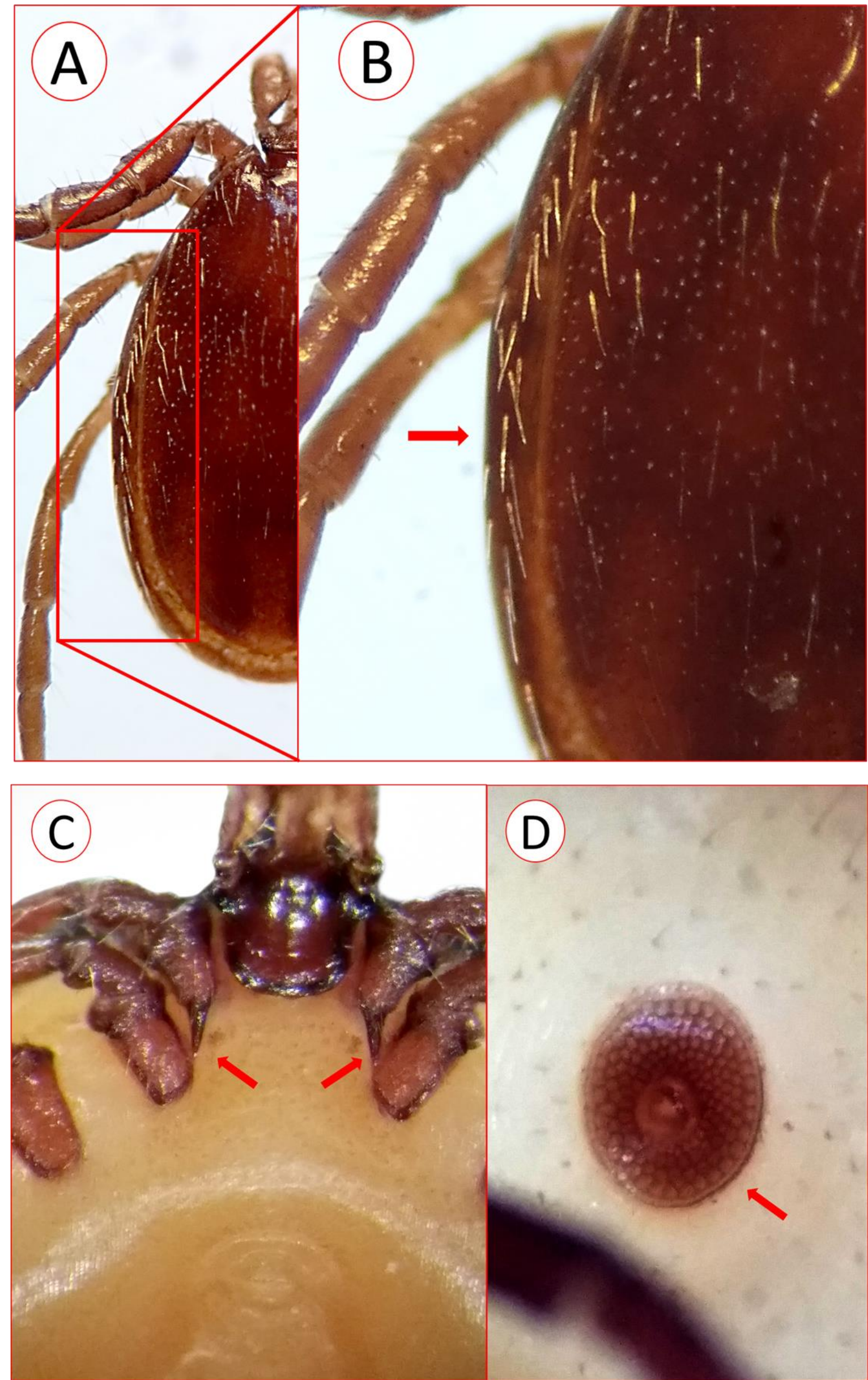

Figure 1. Ixodes inopinatus A. Dorsal view of male, B. One row of seta in the lateral margin of the conscutum of male, C. Internal spurs of coxa I of female, D. Spiracular plate with four concentric rows goblets of female. 

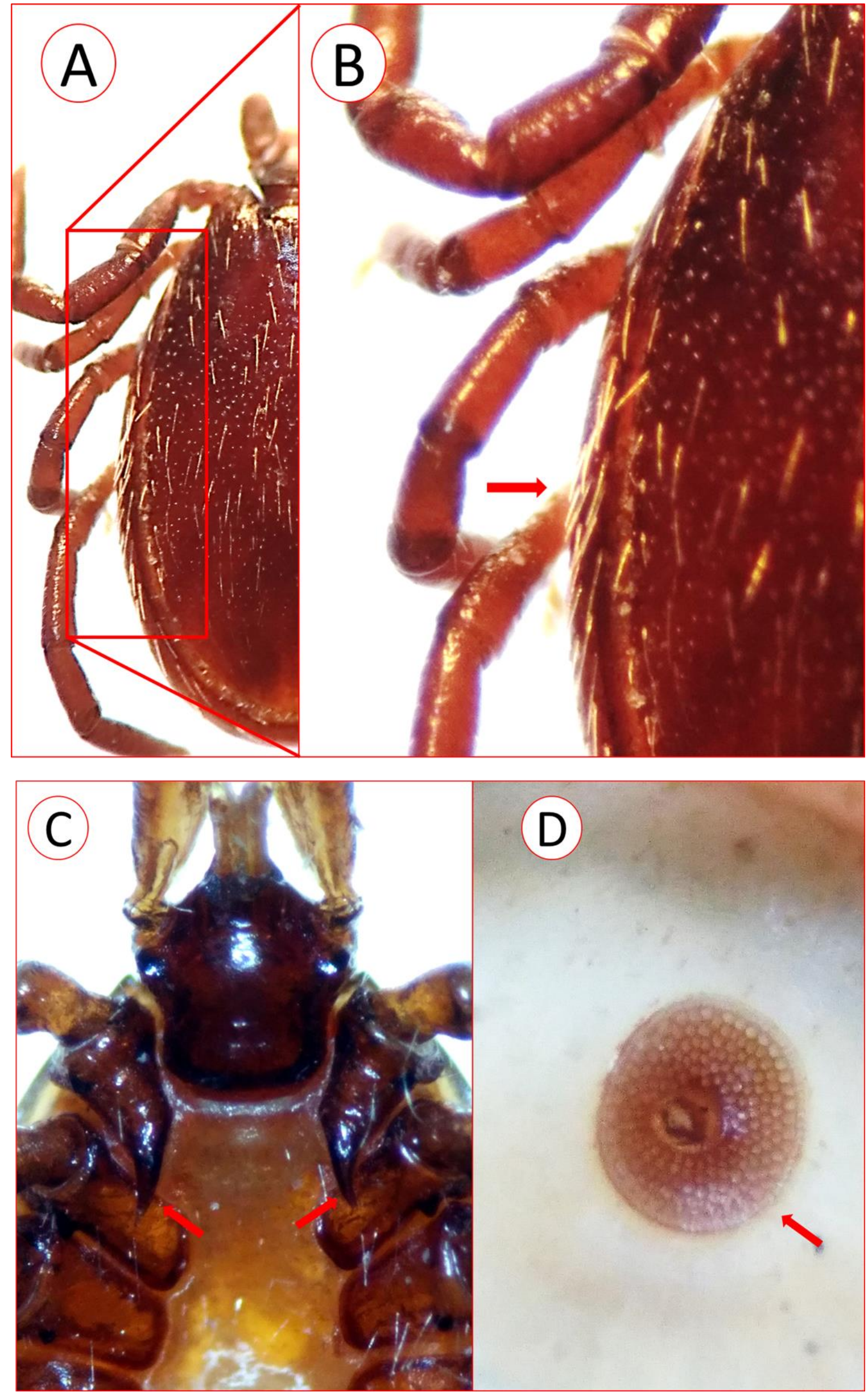

Figure 2. Ixodes ricinus A. Dorsal view of male, B. Several rows of setae in the lateral margin of the conscutum of male, C. Internal spurs of coxa I of female, D. Spiracular plate with concentric five rows goblets of female. 
are less numerous and almost inconspicuous in I. ricinus The internal spur on coxa I has a long tapering pointed internal spur reaching coxa II in I. inopinatus (Fig. 1C), but is longer, curved and touching coxa II in I. ricinus (Fig. 2C) (the internal spur of coxa I only in females is a feature of diagnostic importance). In the female of I. inopinatus, there are four concentric rows of goblets in the spiracular plate (Fig. 1D), while there are (5 or 6 rows) in the female of I. ricinus (Fig. 2D). The more detailed morphological comparison of $I$. ricinus and I. inopinatus has been given by Estrada-Peña et al. (2014) and Chitimia-Dobler et al. (2018).

As previously reported, I. inopinatus is a species that replaces I. ricinus in drier areas, but a recent study shown that both species can be found sympatric in the humid areas (Younsi et al., 2020). In the present study, I. inopinatus and I. ricinus were collected from Ordu province. This province has a humid climate in nearly whole year. Therefore, this study supports the hypotheses of Younsi et al. (2020) about the sympatric distribution of I. inopinatus and $I$. ricinus ticks in the humid areas. In previous reports, specimens of $I$. inopinatus have been mainly collected by flagging from the vegetation and from some host animals, such as lizards, foxes and sheep (Estrada-Peña et al., 2014; Chitimia-Dobler et al., 2018; Hauck et al., 2019). To the best of our knowledge, I. inopinatus was collected from cattle, for the first time, from Turkey.

We strongly suggest that tick specimens identified as $I$. ricinus in tick collections should be re-examined based on the current taxonomic concepts. The medical importance of I. inopinatus is also currently unknown; therefore, new studies should be aimed at the presence and prevalence of tick-borne pathogens in I. inopinatus.

\section{Funding}

There is no fund for the present study.

\section{Conflict of interest}

No potential conflict of interest was reported by the authors.

\section{Acknowledgements}

This paper was presented at the Ecology 2018 International Symposium, held in Kastamonu, Turkey, 1923 June, 2018, by the first author.

\section{REFERENCES}

Bursali, A., Keskin, A. and Tekin, S. 2012. A review of the ticks (Acari: Ixodida) of Turkey: Species diversity, hosts and geographical distribution. Experimental and Applied Acarology, 57: 91-104. doi:10.1007/s10493-012-9530-4

Chitimia-Dobler, L., Rieß, R., Kahl, O., Wölfel, S., Dobler, G., Nava, S. and Estrada-Peña, A. 2018. Ixodes inopinatus Occurring also outside the Mediterranean region. Ticks and Tick-borne Diseases, 9: 196-200. doi:10.1016/j.ttbdis.2017.09.004
Estrada-Peña, A., Mihalca, A.D. and Petney, T.N. 2017. Ticks of Europe and North Africa: A guide to species identification. Springer, Cham, Switzerland, 404 pp.

Estrada-Peña, A., Nava, S. and Petney, T. 2014. Description of all the stages of Ixodes inopinatus n. sp. (Acari: Ixodidae). Ticks and Tick-borne Diseases, 5: 734-743. doi:10.1016/j.ttbdis.2014.05.003

Filippova, N.A. 1977. Ixodid ticks (Ixodinae). Fauna USSR New Ser, 4 (4). Nauka, Moscow, Leningrad, Russia, 316 pp.

Guglielmone, A.A., Apanaskevich, D.A., Estrada-Peña, A., Robbins, R.G., Petney, T.N. and Horak, I.G. 2014. The hard ticks of the world: (Acari: Ixodida: Ixodidae). Springer, Dordrecht, The Netherlands, 738 pp.

Guglielmone, A.A., Sánchez, M.E., Franco, L.G., Nava, S., Rueda, L.M. and Robbins, R.G. 2020. Names of species of hard ticks. Instituto Nacional de Tecnologia Agropecuária, Rafaela, Argentina. Available from: http://rafaela.inta.gob.ar/nombresgarrapatas/ (Last accessed: April 29, 2020)

Hauck, D., Springer, A., Pachnicke, S., Schunack, B., Fingerle, V. and Strube, C. 2019. Ixodes inopinatus in northern Germany: Occurrence and potential vector role for Borrelia spp., Rickettsia spp., and Anaplasma phagocytophilum in comparison with Ixodes ricinus. Parasitology Research, 118: 3205-3216. doi:10.1007/s00436-019-06506-4

Kar, S., Yılmazer, N., Akyıldız, G. and Gargılı, A. 2017. The human infesting ticks in the city of Istanbul and its vicinity with reference to a new species for Turkey. Systematic and Applied Acarology, 22: 2245-2255. doi:10.11158/saa.22.12.14

Karaman, E., Kandemir, N.İ., Yüce, T. and Genç, G. 2012. The nature tourism master plan of Ordu province, 2013-2023. Republic of Turkey Ministry of Agriculture and Forestr, General Directorate of Nature Conservation and National Parks, XI. Regional Directorate, Ordu Branch Office, Ordu, Turkey, 123 pp. [In Turkish]

Keskin, A. and Erciyas-Yavuz, K. 2019. Ticks (Acari: Ixodidae) parasitizing passerine birds in Turkey with new records and new tick-host associations. Journal of Medical Entomology, 56: 156-161. doi:10.1093/jme/tjy151

Keskin, A., Koprulu, T.K., Bursali, A., Ozsemir, A.C., Yavuz, K.E. and Tekin, S. 2014. First record of Ixodes arboricola (Ixodida: Ixodidae) from Turkey with presence of Candidatus Rickettsia vini (Rickettsiales: Rickettsiaceae). Journal of Medical Entomology, 51: 864-867.

doi:10.1603/ME13169

Onofrio, V.C., Guglielmone, A.A., Barros-Battesti, D.M., Gianizella, S.L., Marcili, A., Quadros, R.M., Marques, S. and Labruna, M.B. 2020. Description of a new species 
of Ixodes (Acari: Ixodidae) and first report of Ixodes lasallei and Ixodes bocatorensis in Brazil. Ticks and Tick-borne Diseases, 11: 101423

doi:10.1016/j.ttbdis.2020.101423

Orkun, Ö. and Karaer, Z. 2018. First record of the tick Ixodes (Pholeoixodes) kaiseri in Turkey. Experimental and Applied Acarology 74: 201-205.

doi:10.1007/s10493-018-0219-1
Younsi, H., Fares, W., Cherni, S., Dachraoui, K., Barhoumi, W., Najjar, C. and Zhioua, E. 2020. Ixodes inopinatus and Ixodes ricinus (Acari: Ixodidae) are sympatric ticks in North Africa. Journal of Medical Entomology, 57: 952-956

doi:10.1093/jme/tjz216

Edited by: Kosta Y. Mumcuoglu

Reviewed by: Two anonymous referees

Citation: Bursalı, A., Tekin, Ş. and Keskin, A. 2020. A contribution to the tick (Acari: Ixodidae) fauna of Turkey: The first record of Ixodes inopinatus Estrada-Peña, Nava \& Petney. Acarological Studies, 2 (2): 126-130. 